\title{
Efficacy of Burst Mode Torsional Phacoemulsification in Age-Related Cataract Masum MAA ${ }^{1}$, Khan $\mathrm{MKH}^{2}$, Hasan $Z^{3}$, Kajmina ${ }^{4}$ DOI: https://doi.org/10.3329/jafmc.v15i1.48655
}

\begin{abstract}
Introduction: Torsional ultrasound energy and burst mode interrupted energy delivery system are recent advancementsin the technique of phacoemulsification surgery. It has been reported that both these advancementshelpto reduce corneal wound burn and thermal induced endothelial cell loss and thereby helps to achieve excellent early postoperative visual outcome.
\end{abstract}

Objectives: To evaluate the efficacy of burst mode torsional phacoemulsification surgery in age-related cataract.

Materials and Methods: Prospective observational study of 120 cases thatunderwent phacoemulsificationcataractsurgery in which torsional energy was used in burst mode. Phacoemulsification was performed by "vertical -chop" technique. Intraoperatively corneal wound burn, Descemet's membrane detachment, posterior capsule ruptureetc.were evaluated. Postoperatively corneal oedema, best corrected visual acuity, cystoid macular oedema were evaluated. Postoperatively eyes were examined at day 1,1 week, 6 weeks and 3 months.

Results: Mean age of the patients was $57.28 \pm 8.20$ years. Most of the patients $81(67.5 \%)$ had nuclear sclerosis grade-Il cataract. Intraoperatively, moderate wound burn occurred in 02(1.6\%) eyes, localized Descemet's membrane detachmentin 03(2.5\%) eyes and posterior capsule rupture occurred in $03(2.5 \%)$ cases. Postoperatively, moderate and severe corneal edema was found in $06(5.0 \%)$ and $04(3.3 \%)$ eyes respectively at day 1 . At the end of 3 months follow-up, 114(95\%) eyes maintained a best corrected visual acuity of $\geq 6 / 18$, of which $109(90.8 \%)$ eyes achieved $\geq 6 / 9$.

Conclusion: Burst mode torsional phacoemulsfication is a very effective and advanced technique of cataract surgery. Intraoperative complications are very less and visual outcome is excellent.

Key-words: Torsional energy, Burst mode, corneal edema.

\section{Introduction}

Phacoemulsification is the preferred technique of cataract surgery in the developed world and tertiary centers of developing countries $^{1}$. Likewise, it is the preferred technique of cataract surgery in $\mathrm{CMH}$ Dhaka as well. For many years longitudinal ultrasound was the only ultrasound modality available for phacoemulsification, but recently torsional mode has been developed. In longitudinal ultrasound mode, the phaco tip emulsifieslens material only during forward movement. During backward movement, it only causes friction and heat production. On the other hand, torsional ultrasound energy works by its side-to-side oscillatory shearing action. Lens material is cut in both directions. So torsional ultrasound increases cutting efficiency and reduces the risk of thermal injury by reducing the frictional movements within the incision ${ }^{2}$. Han et al study showed that torsional phacoemulsification generates less heat than longitudinal phacoemulsification ${ }^{3}$.

Moreover, previously longitudinal ultrasound was available only in continuous mode. But now interrupted energy like pulse mode, burst mode are also available. The continuous mode provides continuous delivery of ultrasound energy that causes generation of heat. The Burst mode has got "phaco-on"and"phaco-off" period. It allows the phaco needle to cool during periods of "phaco-off". This helps to reduce thermal damage to the incision and the endothelial cells $\mathbf{s}^{4}$. Sowhen phacoemulsification surgery is done using torsional energy in burst mode, theoretically there should be further less thermal damage to cornea and postoperative outcome should be better.Therefore, we designed the following prospective study to assess the efficacy of burst mode torsional phacoemulsification surgery in terms of visual outcome, intraoperative and postoperative complications in patients with age related cataract in combined military hospital $(\mathrm{CMH})$ Dhaka.

\section{Materials and Methods}

This prospectiveobservational study was conducted in Department of Ophthalmology of $\mathrm{CMH}$ Dhaka from01 November 2015 to 31 October 2016. The study comprised 120 patients who underwent phacoemulsification cataract surgery during this period. Informed consent was taken from all participants and the study was approved by ethical committee of the institute.Inclusion criteria was age related cataracts of Grade II-IV on scale of I-V. Patients with hypertension and well controlled diabetes mellitus were also included.Complicated and traumatic cataracts, patients with co-existing ocular disease (e.g.glaucoma,pseudo-exfoliation, diabetic retinopathy)were alsoexcluded.

Pre-operative evaluation included Snellen's visual acuity test, slitlamp examination including examination with +90D lens, dilated fundoscopy, applanation tonometry, keratometry, optical biometry and sac patency test. SRK-T formula was used to calculate the IOL power.Systemic evaluation included checking of blood pressure, blood sugar and ECG. All the data were recorded in a predesigned data collection sheet. Computer based statistical

1. Lt Col Md Abdullah Al Masum, MBBS, MCPS, DO, FCPS, Classified Specialist in Ophthalmology, CMH, Dhaka (E-mail: masum1023@yahoo.com) 2. Brig Gen Md Kamrul Hasan Khan, MBBS, DO, FCPS, Adviser Specialist in Ophthalmology, CMH, Dhaka 3. Col Zulfikar Hasan, MBBS, DO, FCPS, Classified Specialist in Ophthalmology, CMH, Dhaka 4. Lt Col Natasha Kajmina, MBBS, DO, FCPS, Classified Specialist in Ophthalmology, CMH, Dhaka. 
software SPSS (version 16) was used for data analysis. All surgeries were performed by single surgeon (Principal author) under peribulbar anaesthesia.

Surgical technique: Surgery wasperformed through a $2.4 \mathrm{~mm}$ superotemporalor superiorclear corneal incision. Anterior capsule was stained andcontinuous curvilinear capsulorhexis (CCC) was made. Hydrodissection and nuclear rotation was performed. Phacoemulsification was performed using torsional energy in burst mode (300 ms on, $50 \mathrm{~ms}$ off). Nucleus was divided into 6-8 small fragments by "vertical chopping" and the fragments were removed at the supracapsular or iris plane. Intraoperatively, corneal wound burn was noted and subjectively graded as follows: mild - tissue whitening, moderate - tissue pouting and severe - tissue fish mouthing ${ }^{5}$. Cortex was removed thoroughly and posterior capsule was polished when needed. Single-piece foldable IOL was implanted in the bag and residual OVD was removed. Injection Ceftazidime $(1.0 \mathrm{mg} / 0.1 \mathrm{ml})$ was injected intracamerally. Incisions were sealed by stromal hydration. $5 \%$ povidone iodine was instilled in the conjunctival sac and eye was kept patched for 24 hours.

Table-l: showing the parameters used during different steps of the surgery.

\begin{tabular}{|l|c|c|c|c|}
\hline \multicolumn{1}{|c|}{ Steps } & $\begin{array}{c}\text { Ultrasound } \\
\text { energy (\%) }\end{array}$ & $\begin{array}{c}\text { Vacuum }(\mathrm{mm} \\
\mathrm{Hg})\end{array}$ & $\begin{array}{c}\text { Aspiration flow } \\
\text { rate (cc/min) }\end{array}$ & $\begin{array}{c}\text { Bottle height } \\
(\mathrm{cm})\end{array}$ \\
\hline Sculpting & $30-60$ & 40 & 20 & 5060 \\
\hline Chopping & $30-40$ & $300-500$ & 20 & 90 \\
\hline Fragment removal & $30-50$ & $300-350$ & 20 & 90100 \\
\hline Cortex removal & - & 300 & $20-25$ & 100 \\
\hline Posterior capsule polishing & - & 06 & 05 & 90 \\
\hline OVD removal & - & 400 & 30 & 90 \\
\hline
\end{tabular}

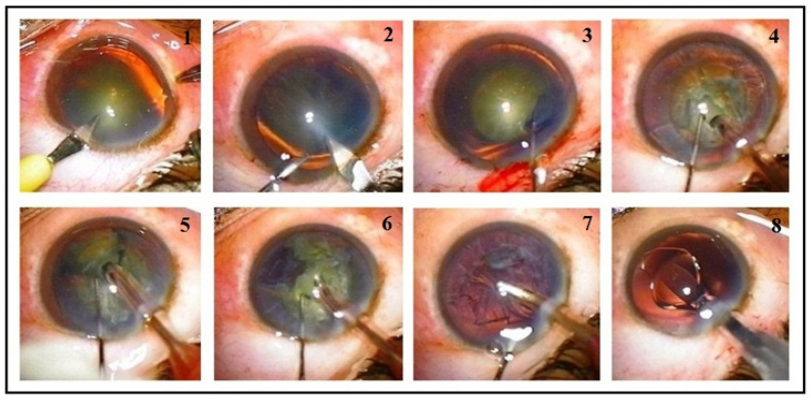

Figure-1: Main steps of surgery: 1 . Side port entry 2 . Clear corneal incision 3. Continuous curvilinear capsulorhexis 4. Sculpting 5. Vertical chop 6. Quadrant removal 7. Cortex clean up 8. Foldable IOL implantation

Postoperatively oralciprofloxacin, topical moxifloxacin $(0.1 \%)$ and topical prednisolone $(1 \%)$ were prescribed. Topical prednisolone was tapered over 6 weeks. Eyes were examined at day 1, 1 week, 6 weeks and 3 months postoperatively.Based on the slit-lamp examinationfindings,corneal edema was defined as an increase in the central corneal thickness with or without Descemet'sfolds6. The corneal thickness was compared to the fellow eye.Corneal edema was graded as trace; where there was minimal corneal clouding and thickening close to incision sites, mild - corneal clouding and thickening affecting less than $25 \%$ of the cornea with no Descemet's folds and clear iris details, moderate-corneal clouding and thickening affecting more than $25 \%$ of the cornea with few Descemet's folds and hazy iris details and severe-corneal clouding and thickening affecting more than $50 \%$ of the cornea with more Descemet's folds and no view of iris details7. Best corrected visual acuity (BCVA) was analyzed at 6 weeks. Posterior capsular opacification (PCO) was examined at 3 months.

\section{Results}

Out of 120 patients, 82 were male and 38 female and mean age was $57.28 \pm 8.20$ years. Most of the patients were retired soldiers $56(46.6 \%)$ and parents of serving soldiers $48(40.0 \%)$. Preoperative best corrected visual acuity was $<6 / 60$ in $27(22.5 \%)$ eyes, between 6/60-6/24 in 87(72.5) eyes and between 6/18-6/12 in 6(5\%) eyes. Most of the patient $81(67.5 \%)$ had nuclear sclerosis grade-II and among these 24(20.0\%) patient had posterior subcapsular cataract also (Table-II). Intraoperatively, mild wound burn occurred in $08(6.4 \%)$ eyes and moderate wound burnoccurred in $02(1.6 \%)$ eyes. Severe wound burn didn't occur in any eye. Localized small Descemet's membrane detachment (DD) adjacent to main incisionoccurred in $3(2.4 \%)$ eyes. Capsulorhexis could not be completed in 02(0.6\%) eyes. Among major complications, posterior capsule rupture with vitreous loss occurred in $3(2.5 \%)$ eyes and nucleus drop occurred in $1(0.8 \%)$ eye. Postoperatively, severe corneal oedema occurred in $3(2.5 \%)$ eyes. Cystoid macular oedema developed in $03(2.5 \%)$ cases. Endophthalmitis did not occur in any case of our study. Significant post-operative astigmatism ( $\geq 1.5 \mathrm{D})$ was found in $7(5.8 \%)$ cases and $4(3.2 \%)$ cases shown biometric surprise ( $\geq+1.0 \mathrm{D}$ Sph for distant correction). Post-operative posterior capsule opacification (PCO) developed in 4(3.2\%) eyes by 3 months (Table-III). About $114(95.2 \%)$ eyes achieved BCVA $\geq 6 / 18$ at 3 months and among these $109(90.8 \%)$ cases achieved BCVA $\geq 6 / 9$ (Table-IV).

Table-II: Describes morphology and grading of the cataract $(n=120)$

\begin{tabular}{|l|c|c|}
\hline \multicolumn{1}{|c|}{ Grade } & Frequency & Percentage \\
\hline Grade-II nuclear sclerosis & 57 & 47.5 \\
\hline Grade-II nuclear sclerosis + PSC & 24 & 20.0 \\
\hline Grade-III nuclear sclerosis & 33 & 27.5 \\
\hline Grade-IV nuclear sclerosis & 6 & 5.0 \\
\hline
\end{tabular}

- $\quad P S C=$ Posterior sub-capsular cataract

Table-III: Distribution of patients by intra-operative and postoperative complications $(n=120)$

\begin{tabular}{|l|l|c|c|}
\hline \multicolumn{2}{|l|}{ Complications } & Frequency & Percentage \\
\hline \multirow{4}{*}{$\begin{array}{l}\text { Intra-operative } \\
\text { Minor complications }\end{array}$} & Short corneal tunnel & 02 & 1.6 \\
\cline { 2 - 4 } & Mild wound burn & 08 & 6.4 \\
\cline { 2 - 4 } & Moderate wound burn & 02 & 1.6 \\
\cline { 2 - 4 } & Localized Descemet's detachment & 03 & 2.5 \\
\cline { 2 - 4 } & Failure to complete capsulorhexis & 02 & 1.6 \\
\cline { 2 - 4 } & Anterior capsule split & 02 & 1.6 \\
\cline { 2 - 4 } & Breaking of trailing haptic of IOL & 02 & 1.6 \\
\hline \multirow{4}{*}{ Intra-operative Major } & PC Tear with vitreous loss & 03 & 2.5 \\
\cline { 2 - 4 } & Nucleus drop & 01 & 0.8 \\
\hline \multirow{4}{*}{$\begin{array}{l}\text { Postoperative } \\
\text { complications }\end{array}$} & Moderate corneal oedema & 6 & 5.0 \\
\cline { 2 - 4 } & Severe corneal oedema & 3 & 2.5 \\
\cline { 2 - 4 } & Up-drawn pupil & 2 & 1.6 \\
\cline { 2 - 4 } & Postoperative astigmatism ( $\geq 1.5 \mathrm{D})$ & 7 & 5.8 \\
\cline { 2 - 4 } & Biometric surprise ( $\geq+1.0 \mathrm{D}$ Sph) & 4 & 3.2 \\
\cline { 2 - 4 } & Cystoid macular oedema & 3 & 2.5 \\
\cline { 2 - 4 } & Posterior capsular opacity & 4 & 3.2 \\
\hline
\end{tabular}


Table-IV: Postoperative visual outcome $(n=120)$

\begin{tabular}{|l|c|c|c|c|}
\hline & \multicolumn{2}{|c|}{ UCVA } & \multicolumn{2}{c|}{ BCVA } \\
\hline \multicolumn{1}{|c|}{ VA } & $n$ & $\%$ & $n$ & $\%$ \\
\hline $6 / 9-6 / 6$ & 84 & 70.0 & 109 & 90.8 \\
\hline $6 / 18-6 / 12$ & 22 & 18.3 & 05 & 4.2 \\
\hline $6 / 60-6 / 24$ & 12 & 10.0 & 05 & 4.2 \\
\hline$<6 / 60$ & 02 & 1.7 & 01 & 0.8 \\
\hline
\end{tabular}

Note: $V A=$ Visual acuity, UCVA = Uncorrected visual acuity, $B C V A=$ Best corrected visual acuity

\section{Discussion}

The transition from longitudinal movement to side-to-side (torsional) movement of the phaco tip has made ultrasound more efficient and productive with lower parameters.Torsional phacoemulsification decreases frictional heat generation, minimizes repulsion of nuclear material and improves cutting ability ${ }^{8}$. Thereby modern phacoemulsification technique causes a lower incidence of corneal wound burn. Several studies have published different rates of corneal wound burn during phaco surgery. The largest survey in the United States and Canada documented an incidence of $0.037 \%$ of severe corneal wound burn requiring suture ${ }^{9}$. Bradley \& Olson reported an incidence of moderate-to-severe wound burn in $0.001 \%$ cases $^{10}$. In this study, although severe wound burn didn't occur in any eye, moderate wound burn occurred in $02(1.6 \%)$ eyes. Mild wound burn which is negligible occurred in $08(6.4 \%)$ eyes. Compared to Bradely \& Olson study, our wound burn was much higher because of lack of experience of a beginner surgeon.

Transientcorneal edemais very common after phacoemulsification. However, this edema tends to resolve within the first postoperative week. So, here we did not report the mild corneal edema. In Tesausis et al study, the incidence of severe corneal edema was $4.5 \%{ }^{11}$. Ali et al studied on incidence of corneal edema after phacoemulsification surgery done by beginner phaco surgeons. $22 \%$ patients of their study had moderate corneal edema ${ }^{12}$. In this study also the surgeon was a beginner phaco surgeon. Even though only $06(5.0 \%)$ eyes developed moderate corneal edema and $3(2.5 \%)$ eyes developed severe corneal edema which is comparable to Tesausis et al study, but better than Ali et al study. Kim et al, studied corneal astigmatism after cataract surgery done by temporal clear corneal incision, The average magnitudes of surgically induced astigmatism and long-term astigmatism change were $0.66 \pm 0.42$ and $0.57 \pm 0.47 \mathrm{D}$, respectively ${ }^{13}$. In this study, postoperative astigmatism of $\geq 1.50 \mathrm{D}$ was found in 07 $(5.8 \%)$ eyes. Amount of astigmatism is little higher in this study than other study because we did not use temporal incision.

Several studies onposterior capsule rupture and vitreous loss rates have been published. The rate of vitreous loss in these studies consistently ranges from $1 \%$ to $4 \%$. Narendran and coauthors conducted a study in United Kingdom in 2009 that reports a $1.9 \%$ rate of vitreous loss ${ }^{14}$. Greenberg and colleagues' study conducted in US that was published in 2011 found a 3.5\% rate of vitreous loss ${ }^{15}$. In this study, posterior capsule rupture with vitreous loss occurred in $3(2.5 \%)$ eyes which are well acceptable.
Nucleus drop is one of the most dreaded complications of modern cataract surgery. The published incidence of nucleus drop ranges from $0.3 \%$ to $1.1 \%{ }^{16}$. In this study, nucleus drop happened in one $(0.8 \%)$ case which is well within the reported range. Not a single case of our study suffered with postoperative endophthalmitis. Cystoid macular edema (CME), which was confirmed by fundus flouresceinangiography, was found in $03(2.5 \%)$ cases. Ursell et al report a 19\% angiographic CME although clinical CME was not seen in any of their patients after phacoemulsification ${ }^{17}$.

The rate of posterior capsular opacity (PCO) in modern phaco surgery ranges from $0 \%$ to $6.2 \%{ }^{15}$. In this study, PCO developed only in $4(3.2 \%)$ cases. Probably low PCO rate in this study was due to thorough cortical clean-up. Of course, 3 months is a very short period to observe the PCO development. This is a limitation of this study. Regarding visual outcome in this study, 106(88.3\%) eyes achieved UCVA $\geq 6 / 18$ and 114 (95.0\%) achieved BCVA $\geq 6 / 18$ at 3 months. This outcome is similar with Oderinlo et al study in which $85.9 \%$ of patients had UCVA $\geq 6 / 18$ and $98.0 \%$ of patients had BCVA $\geq 6 / 18$ at 3 months ${ }^{18}$. According to WHO standard, at the end of 3 months follow-up, $95.0 \%$ eyes of our study achieved good visual outcome, $4.2 \%$ had borderline and only $1.8 \%$ eyes had poor outcome ${ }^{19}$. This outcome is similar to that of Hashmiet alstudy in which $93.3 \%$ of the operated eyes had good visual outcome, while $4.4 \%$ and $2.2 \%$ had borderline and poor outcomes ${ }^{20}$.

\section{Conclusion}

Burst mode torsional phacoemulsification surgeryis a very effective and advanced technique of cataract surgery.Corneal burn and other intraoperative complications are very less and visual outcome is excellent.

\section{References}

1. Linebarger EJ, Hardten DR, Shah GK et al. Phacoemulsification and modern cataract surgery. Surv Ophthalmol 2000; 44:541-42.

2. Doors M, Berendschot TT, Touwslager W et al. Phacopower modulation and the risk for postoperative corneal decompensation: A randomized clinical trial. JAMA Ophthalmol 2013; 131:1443-50.

3. Han YK, Miller KM. Heat Production: Longitudinal versus torsional phacoemulsification. J Cataract Refract Surg 2009; 35:1799-1805.

4. Vasavada AR, Vasavada VA. Fundamentals of power modulation. Cataract \& Refractive Surgery Today Europe. July/August 2014; 69-71.

5. Dholakia SA, Vasavada AR. Intraoperative performance and longterm outcome phacoemulsification in age-related cataract. Indian Journal of Ophthalmology2004; 52:311-317.

6. Lundberg B, Jonsson M, Behndiq A. Postoperative corneal swelling correlates strongly to corneal endothelial loss after phacoemulsification cataract surgery. Am J Ophthalmol 2005; 139:1035-41.

7. Ahmed M, KotbEM, Gamil MM. Torsional Mode Phacoemulsification: Effective, Safe Cataract Surgery Technique of the Future.Middle East Afr J Ophthalmol 2010; 17(1):69-73.

8. Davison JA. Cumulative tip travel and implied followability of longitudinal and torsional phacoemulsification. J Cataract Refract Surg 2008; 34:986. 
9. Sorensen T et al. J Cataract Refract Surg 2012; 38(2):227-33.

10. Bradley MJ, Olson RJ. A survey about phacoemulsification incision thermal contraction incidence and causal relationships. Am J Ophthalmol 2006; 141:222-4.

11. Tsaousis KT, Panagiotou DZ, Kostopoulou E et al. Corneal oedema after phacoemulsification in the early postoperative period: A qualitative comparative case-control study between diabetics and non-diabetics. Ann Med Surg (Lond) 2016; 5:67-71.

12. Ali A, Ahmet T, Ahmed T. Corneal problems during and after phacoemulsification by beginner phacoemulsification surgeon. Pak $\mathrm{J}$ Med Sci 2007; 23:401-4.

13. Hyojin K, Woong-Joo W, Choun-Ki J. Corneal astigmatism in patients after Cataract surgery: A 10-year follow-up study. J Refract Surg 2016; 32(6):404-9.

14. Narendran N, Jaycock P, Johnston RL et al. The Cataract National Dataset electronic multicentre audit of 55,567 operations: Risk stratification for posterior capsule rupture and vitreous loss. Eye (Lond) 2009; 23(1):31-7.
15. Greenberg PB, Tseng VL, Wu WC et al. Prevalence and predictors of ocular complications associated with cataract surgery in United States veterans. Ophthalmology 2011; 118(3):507-14.

16. Mahmood S, von Lany $\mathrm{H}$, Cole MD et al. Displacement of nuclear fragments into the vitreous complicating phacoemulsification surgery in the UK: incidence and risk factors. Br J Ophthalmol 2008; 92(4):488-492.

17. Ursell PG, Spalton DJ, Whitcup SM. Cystoid macular edema after phacoemulsification: Relationship to blood-aqueous barrier damage and visual acuity. J Cataract Refract Surg 1999; 25:1492-7.

18. Oderinlo $\mathrm{O}$, Hassan $\mathrm{AO}$, Oluyadi $\mathrm{FO}$ et al. Refractive aim and visual outcome after phacoemulsification: A 2-year review from a Tertiary Private Eye Hospital in Sub-Saharan Africa. Niger J Clin Pract 2017; 20:147-52.

19. Community Eye Health 2003; 16(48):49-64.

20. Hashmi FK, Khan QA, Chaudhry TA et al. Visual Outcome of Cataract Surgery. Journal of the College of Physicians and Surgeons Pakistan 2013; 23(6):448-9. 